\title{
Cidade de Deus em foco - Análise de representações de jovens da periferia
}

\author{
Aline Silva Correa Maia ${ }^{1}$
}

Resumo: Mesmo tratando-se de uma obra de ficção, muitas vezes o cinema reforça representações que reverberam preconceitos enraizados no imaginário coletivo brasileiro; por exemplo, ao retratar a periferia. Sob este aspecto, pretendemos analisar, neste artigo, a juventude suburbana inscrita em Cidade de Deus (Fernando Meirelles, 2002) a fim de destacar elementos fundamentais para a identificação dos sujeitos, para a criação da memória coletiva e para a elaboração da identidade social.

Palavras-chave: Juventude. Periferia. Representação e Identidade. Cinema brasileiro.

\begin{abstract}
Even when dealing with fiction, cinema many times reinforces representations which reverberate prejudices well settled in the Brazilian collective imaginary. For instance, when portraying periphery. From this point of view, this article intends to analyze, the suburban youth in "Cidade de Deus" (Fernando Meirelles, 2002), in order to highlight fundamental elements for subject identification, for collective memory creation and for social identity elaboration.

Key words: Youth. Periphery. Representation and identity. Brazilian cinema.
\end{abstract}

Resumen: Aun cuando se trata de ficción, el cine muchas veces refuerza las representaciones que repercutirá prejuicios asentada en el imaginario colectivo brasileño, por ejemplo, al retratar periferia. Desde este punto de vista, este artículo tiene como objetivo analizar, en la suburbana juventud "Cidade De Deus" (Fernando Meirelles, 2002), con el fin de destacar los elementos fundamentales para el tema de identificación, para la creación de la memoria colectiva y la elaboración de la identidad social.

Palabras clave: Juventud. Periferia. Representación y identidad. Cine brasileño.

Résumé: Même lorsque traitant la fiction, le cinéma beaucoup de fois renforce les représentations qui réverbèrent des préjudices bien arrangés dans l'imaginaire collectif brésilien. Par exemple, en dépeignant la périphérie. De ce point de vue, cet article prévoit pour analyser, la jeunesse suburbaine dans "Cidade de Deus" (Fernando Meirelles, 2002), afin d'accentuer les éléments fondamentaux pour l'identification soumise, pour la création collective de mémoire et pour l'élaboration sociale d'identité.

Mots clés: Jeunesse. Périphérie. Représentation et identité. Cinéma brésilien.

\section{Introdução}

Matriz do imaginário coletivo, o cinema pode ser visto como produtor e refletor de identidades que evidenciam novos sujeitos na cena cultural. O discurso cinematográfico provoca algum tipo de reconhecimento de uma dada realidade. Na tela, o que se passa é uma série de imagens justapostas e bem editadas que poderá desencadear a projeção de

\footnotetext{
${ }^{1}$ Jornalista graduada na Faculdade de Comunicação da Universidade Federal de Juiz de Fora UFJF; mestranda em Comunicação e Sociedade do PPGCom-UFJF; produtora TV Panorama afiliada Rede Globo. Desenvolve pesquisas na linha de Comunicação e Identidades. E-mail: nininha_m@ig.com.br / ninemaia@hotmail.com
} 
quem a assiste na própria história contada. Se a comunicação de massa é reprodutora da cultura, o cinema sob este aspecto deve ser visto.

Sendo a cinematografia integrante da indústria cultural, os temas a serem abordados precisam chamar atenção, causar impacto de alguma forma. Neste contexto, percebemos a preferência, muitas vezes, pela retratação de temáticas ligadas à violência, ao que está no limite das instituições sociais, ao exótico. Nesta linha, boa parte dos filmes vai abordar o diferente. Não necessariamente objetivando incitar o público a refletir, mas evidenciando a diversidade e a diferença em contraste à norma social prevalecente. A dramaticidade visual e auditiva é requisito imprescindível para a eficácia e potencialização do efeito de realidade inerente à construção de representações sociais das mídias de massa audiovisuais.

Dado que os meios de comunicação massivos, entre eles o cinema, são agentes significantes, fabricantes de sentidos que não apenas reproduzem a realidade, mas também a definem, é a partir da juventude da favela inscrita no filme Cidade de Deus (Fernando Meirelles, 2002) que pretendemos analisar, neste artigo, a construção identitária do jovem da periferia. Entre tantos enfoques possíveis, optamos por avaliar as representações juvenis a fim de destacar elementos fundamentais para a identificação dos sujeitos, para a criação da memória coletiva e para a elaboração da identidade social.

Desde o final da década de 90, atos violentos envolvendo classes populares são imagens recorrentes no cinema brasileiro, sejam em narrativas ficcionais ou documentais. Escolhemos trabalhar com Cidade de Deus, de Fernando Meirelles e co-direção de Kátia Lund, exatamente por ser um exemplo de produção com este enquadramento, tendo na classe subalterna seus protagonistas, expostos com admiração e como espetáculo. O filme pode ser entendido como o olhar da classe média sobre a periferia, onde a favela é o caos e os traficantes tomam conta de tudo, decidindo inclusive quem deve viver e quem deve morrer. A obra, cuja produção teve um custo total de U\$ $3.300 .000,00^{2}$, não aborda os conflitos entre o subúrbio e o centro, mas a guerra travada entre traficantes do complexo habitacional que dá nome ao filme. Longe do cartão postal carioca, o lugar serve de fonte para a burguesia consumidora de drogas.

\footnotetext{
${ }^{2}$ Valor informado no site oficial do filme: http://cidadededeus.globo.com/
} 
Representante do Cinema de Retomada ${ }^{3}$, Cidade de Deus é senão várias histórias de moradores narradas por um jovem, Buscapé, que também reside no bairro. Contar a trajetória de seus habitantes é também revelar como surgiu a favela, bem como traçar a evolução da violência e do tráfico de drogas no lugar. A narração da memória permite a partilha de lembranças que serão apropriadas pelo ouvinte - o telespectador. Ao relatar as histórias - mesmo as individuais, mas representativas de uma experiência coletiva Buscapé colabora para a transmissão de uma tradição, produzindo sentidos que reforçam preconceitos arraigados no imaginário social brasileiro. Constrói-se um discurso sobre a realidade na qual se acentua que o papel do jovem da periferia está restrito, em geral, ao banditismo e à marginalidade.

Como vivemos em uma sociedade em que as relações sociais são cada vez mais mediadas, percebemos a importância em apontar como uma realidade apresentada a partir de uma determinada angulação, ainda que em um produto ficcional, é capaz de formar opiniões e reforçar papéis sociais. Para nossa reflexão, enfocaremos, principalmente, duas figuras do filme: Buscapé e Zé Pequeno.

Consideramos importante ressaltar, ainda, que o filme Cidade de Deus é baseado em fatos reais, fundamentado no romance homônimo do antropólogo Paulo Lins, que viveu 20 anos na favela carioca para escrevê-lo. Uma centena de garotos da periferia do Rio de Janeiro participou do elenco, cuja seleção priorizou atores não profissionais. O diretor Fernando Meirelles queria “que o espectador visse o Zé Pequeno e não uma extraordinária interpretação do Zé Pequeno. Queria que o espectador se relacionasse diretamente com os personagens, sem filtros ${ }^{4 »}$.

\section{Representação e Identidades}

Uma faca sendo amolada, pagode, churrasco, pandeiro, galinha morta, galinha fugindo. Seqüência de imagens que culmina com um bando de crianças e de adolescentes em disparada atrás da ave fujona. Cenas curtas, picotadas e bem editadas como na publicidade $^{5}$. A perseguição tem fim quando o paredão da Cidade de Deus é formado. De

\footnotetext{
${ }^{3}$ Etapa do cinema brasileiro a partir da década de 90, quando houve um boom de produções visivelmente comerciais, após longo período de dificuldades enfrentadas pelo setor, que viu a extinção da Embrafilme, Concine e Fundação do Cinema Brasileiro durante o mandato de Fernando Collor.

${ }^{4}$ Entrevista do diretor Fernando Meirelles que consta no site http://cidadededeus.globo.com/

${ }^{5}$ Fernando Meirelles é publicitário.
} 
um lado, a juventude armada da periferia, de outro, a polícia e, no meio, a galinha e Buscapé, personagem que nos convida a um retorno ao passado para contar o presente. E é na redescoberta do ontem que compreenderemos as origens das identidades fragmentadas do hoje exibido na tela.

Na narrativa de Buscapé, regressamos aos anos 60, quando dezenas de famílias tiveram que sair de suas casas por causa de enchentes ou incêndios criminosos em outras favelas do Rio de Janeiro. Todas foram encaminhadas para a Cidade de Deus, lugar que é o verdadeiro protagonista do filme. Apoiando-se na própria memória, Buscapé reaviva o passado para constituir o presente e reconstruir as identidades dos personagens que têm suas estórias reveladas.

De acordo com Verônica Sales Pereira (1993), ao questionar suas experiências, um indivíduo passa a refletir sobre sua condição humana e social. No filme, isto é retratado quando Buscapé conta a própria estória. Acostumado a conviver com o banditismo e frente ao desemprego e ao não reconhecimento da sociedade de seu lugar enquanto cidadão, ele decide tornar-se assaltante. Consegue um revólver e sai para o primeiro roubo. Seu contexto provoca fraturas em sua identidade, já que novas experiências são construídas e outras já vividas são desintegradas. Há um verdadeiro processo de transformação - sua identidade é repensada, avaliada, montada e desmontada.

No exemplo de Buscapé, assumir-se bandido não é uma empreitada de sucesso. Ele não consegue cometer os crimes após algumas tentativas, e decide procurar emprego. $\mathrm{Na}$ verdade, ele sempre teve medo de revestir-se ladrão e resignava-se com a possibilidade de estar condenado à violência do lugar que morava. Fortuna do jovem que acabará tornadose fotógrafo profissional ao descobrir que pode ver as mazelas da periferia com outros olhos. É registrando a própria realidade subalterna que ele conseguirá emprego em um jornal.

Há ainda uma outra reflexão originada a partir do comportamento de Buscapé. Adolescente, ele junta-se a um grupo de colegas para ir à praia e fumar maconha. Como analisou Sales Pereira, o sujeito necessita realizar certos ritos da sociedade na qual está inserido. Neste contexto, não temos rito como seguimento religioso, mas como atividade legitimadora e afirmativa de um tempo, de uma situação social, de uma categoria. Por exemplo, no filme, o uso de drogas encerra ritos que parecem fazer parte do cotidiano jovem da periferia. Este comportamento também revela a confirmação de uma identidade 
individual engendrada em um grupo. Os jovens precisam sentir a pertença a um movimento social. Assim, em Cidade de Deus, é em coletividade que eles divertem-se e fumam maconha, por exemplo.

Como propõe Peter Berger (1985), na realidade da vida cotidiana o homem não está só. Ele experiencia o outro face a face, convive, partilha espaço, ações, pensamentos e emoções, interagindo socialmente. Em Cidade de Deus esta participação entre indivíduos se dá, em geral, de forma conflituosa. As relações entre os sujeitos são permeadas pela dinâmica da violência. Desde as crianças aos adultos, percebemos nos personagens marcas da brutalidade imposta pelas situações de abandono social em que vivem. Interessante analisar como é o comportamento de cada indivíduo frente à violência presente em suas vidas. Enfocando especificamente a juventude representada no filme, é possível identificar, em um primeiro momento, três tipos: aquele que se entrega à criminalidade e tem prazer em fazer isso (Zé Pequeno); o traficante "gente boa”, querido por todos e que se torna herói ao ser assassinado por engano (Bené); e o bonzinho que decide lutar contra seu próprio contexto, negando a herança deixada pelo lugar em que vive e buscando estudar, trabalhar e ter uma profissão (Buscapé).

Diferentemente dos demais animais, o ser humano tem uma ocupação diferenciada do e no espaço geográfico: é aberto para o mundo e tem no ambiente um agente participante do seu processo de “tornar-se homem”, como propõe Berger. O ser em desenvolvimento - uma vez que o indivíduo nasce incompleto - também se relaciona com uma ordem cultural e social específica que vai influenciar na sua formação. Ainda crianças, os indivíduos são submetidos à socialização primária, quando são apresentados ao mundo. Neste momento, a criança apropria-se do que lhe é mostrado e passa a acreditar ser aquilo que dizem que ela é. Família e escola detêm esta responsabilidade. Em uma segunda etapa, a da socialização secundária, temos a interiorização dos submundos institucionais através das atividades de subsistência, relacionadas ao trabalho. Por isso, em meio a este ciclo, chamamos a atenção para a violência no local de moradia, fator que pode tornar-se um elemento constituinte da identidade dos adolescentes.

Em Cidade de Deus, desde crianças os indivíduos são expostos às mazelas do mundo. Ou seja, o processo de socialização do sujeito é marcado pelo abandono sóciopolítico. A violência faz-se presente não só através das armas que matam, mas também pela ausência do olhar social: a condição de vida é precária, falta emprego, levando muitos 
a buscar sobrevivência no crime; não há segurança, saúde e educação, fatores que somados a uma estrutura familiar deficiente acarretam em uma socialização incompleta, mal sucedida, que poderá comprometer o reconhecimento do indivíduo, a auto-percepção daquilo que ele é. Os reflexos deste desamparo social são revelados no comportamento da infância e da juventude. É perceptível que os que crescem em meio ao banditismo têm suas identidades influenciadas pela banalização da violência.

O personagem Zé Pequeno, quando criança chamado Dadinho, mostra desde cedo voracidade pelo crime. Palavrões, armas e maconha fazem parte de seu desenvolvimento, como é mostrado no filme. Ainda moleque, sente prazer ao matar dezenas de pessoas em um motel. Cresce com a fama de perigoso, e assim gosta de ser reconhecido e tratado. Não bastassem os assaltos que realizava, já com mais de 18 anos, também decide comandar o tráfico de drogas na favela. Na Cidade de Deus polícia não entra. Não precisa. A ordem é instaurada pelo bando de Zé Pequeno. Ele torna-se a lei. Ele torna-se o juiz e decide quem vive e quem morre. Assaltos não acontecem no complexo habitacional. Quem os pratica é condenado por Zé Pequeno. Pois, sem ocorrências, a Polícia Militar permanecerá longe do lugar e o tráfico poderá fluir normalmente. No filme de Meirelles, Zé Pequeno é a ordem social proposta por Berger. As instituições na favela são criadas e estabelecidas pelo traficante e seus comparsas, que estabelecem quais são os padrões de conduta, todos submissos ao controle social do grupo.

Sendo a sociedade um produto humano e o homem um produto social, num cíclico processo de exteriorização - interiorização indicado por Berger, Cidade de Deus apresenta a violência e o tráfico na favela como conseqüências das ações de seus moradores, bem como os comportamentos arredios da juventude, por exemplo, como resultado da maldade que testemunha e vivencia esta categoria em todos os campos da vida cotidiana. As representações juvenis são feitas a partir dos estímulos recebidos, isso porque os produtos exteriorizados da atividade humana tornam-se realidade através do processo de objetivação, e são reincorporados pelo indivíduo. Se na exteriorização o sujeito entrega à sociedade o resultado de suas atividades, é através da interiorização que ele sente-se parte da sociedade, reconhece-se, identifica-se.

Ao concebermos o mundo como um palco, como sugerido por Goffman (1985), logo identificaremos que cada ser humano é um ator que encena um papel para o público, este, neste contexto definido como o outro. Deste processo, apontamos duas importantes 
noções: a primeira dá conta que desempenhar e interiorizar papéis é participar de um mundo social, além de torná-lo subjetivamente real; a segunda refere-se à compreensão de que a representação de um papel será feita de tal forma a levar o outro a acreditar que somos realmente o que queremos parecer ser. Diante dos outros, fazemos uso de valores tidos como aceitos para que sejamos aprovados por quem nos observa.

No filme em análise, Zé Pequeno age violentamente porque assim quer ser reconhecido. Durante a narração de Buscapé sobre a evolução do bandido, assistimos a uma cena em que moradores da favela parabenizam-no pelo aniversário de 18 anos. É possível ouvir algumas frases como “agora já pode ser preso, hein?!”. Esta passagem reflete exatamente a vontade e necessidade desta figura dramática em assumir o papel de bandido e assim ser identificado, com orgulho. É uma construção simbólica que revela os valores da comunidade na qual o personagem está inserido. Qual não é a alegria de Zé Pequeno ao ver uma foto sua com o seu bando, tirada por Buscapé, estampada na primeira página de um jornal carioca?! O traficante sentiu-se finalmente reconhecido como o bandido perigoso cuja imagem sustentava.

Em meio à realidade subjetiva, a identidade é elemento chave para compreensão da dialética entre natureza e sociedade. Se, de um lado, temos a identidade concebida por processos sociais determinados pela estrutura social, de outro, encontramos a estrutura social remodelada ou mesmo modificada pelas identidades criadas. Receber uma identidade é localizar-se no mundo socialmente criado. Cabe ressaltar que as identidades estão em permanente construção, sujeitas aos deslizamentos e aos deslocamentos. Elas não são, portanto, unidimensionais e fixas; são múltiplas e estão em constante movimento, transformação, nomadismo e tensão. Paisagens culturais que no passado forneciam as bases para a localização dos indivíduos, estão sendo fragmentadas; fato este relacionado a outras duas situações: a transformação estrutural nas sociedades modernas no final do século XX e o abalo de identidades pessoais, afetando a idéia que os indivíduos têm de si próprios. Tal contexto tem construído, segundo Hall (2006), a chamada “crise da identidade".

Homi Bhabha (2005) justifica que o descentramento do sujeito, a partir da queda de conceitos até então rígidos e que serviam de base para a delimitação das identidades (re)conhecidas, colaborou para a percepção de outras categorias identitárias como, por exemplo, aquelas advindas da orientação sexual e da localidade geopolítica. Estas novas 
identidades surgem, segundo o autor, nos entre-lugares: onde se dá a articulação de diferenças culturais.

Para Bhabha, nas relações sociais não há apenas o eu e o outro, mas, existe, também, um terceiro-espaço onde ocorre a negociação, que também podemos entender como concessão, à qual está vulnerável o indivíduo. Em Cidade de Deus, Buscapé decidese por não incorporar a violência de seu local de moradia. Ao contrário de outros personagens mostrados, ele reconhece-se cidadão e corre atrás de seus direitos, como já abordamos anteriormente: quer ter dignidade. É nesta região de fronteira que ele assume-se jovem sem o estigma da periferia e parte em busca de emprego. Buscapé, que encerra o tipo do bom jovem, vê em Zé Pequeno - o traficante que tem prazer em matar - todos os valores que não quer para si. Há o estranhamento, elemento indicado por Bhabha como necessário à construção identitária, pois, segundo o estudioso, é no desejo de conhecer o outro, de “ir além”, que se dá o reconhecimento de si próprio assim como de outras identidades. "O Outro deve ser visto como a negação necessária de uma identidade primordial - cultural ou psíquica - que introduz o sistema de diferenciação que permite ao cultural ser significado como realidade lingüística, simbólica, histórica” (BHABHA, 2005: 86).

Complementando Hall e Bhabha, podemos utilizar as proposições de Zygmunt Bauman (2005) para identidade. De acordo com ele, é possível inferir que todos os sujeitos têm mais de uma identidade, estas, muitas vezes inconciliáveis, de forma que nos encontraremos sempre deslocados, ou seja, não estamos totalmente em lugar algum. Na modernidade líquida ${ }^{6}$, nossa localização é contínua em uma região de barganha, de troca, de maneira que as identidades são flutuantes, nos obrigando sempre a dar explicações e estar em constante negociação.

Segundo Bauman, só despertamos para a questão da identidade quando a noção de pertencimento deixou de ser o único fator para a identificação. Por muito tempo, o Estado significava o elemento de unidade nacional: tinha um passado - que se tornava $\mathrm{O}$ passado compartilhado por seus indivíduos -, definia, classificava e segregava tradições e modos de vida, por exemplo. Uma vez nascido em determinado país, o indivíduo recebia a identidade daquela nação. A “ficção da natividade do conhecimento" era o instrumento de coerção

\footnotetext{
${ }^{6}$ Conceito presente na obra de Bauman e que indica o período de globalização.
} 
dos indivíduos e a noção de identidade era agonística, prolongando o pertencimento devido à ameaça da exclusão. Assim, o Estado controlava as identidades.

Mas, quando a noção de pertencimento entra em crise (o que sou? de onde sou?), coloca em dúvida a interpretação de identidade. Neste contexto, temos novas construções identitárias fluidas e cambiantes, que "flutuam no ar, algumas de nossa própria escolha, mas outras infladas e lançadas pelas pessoas em nossa volta, (...). Há uma ampla probabilidade de desentendimento, e o resultado da negociação permanece eternamente pendente” (BAUMAN, 2005: 19). Na era líquida-moderna, em que nova roupagem é dada às identidades, estas não devem ser incorporadas com "unhas e dentes", como verdade única. Mas é preciso estar pronto para abandonar uma identidade e tão logo assumir outra, pois as “identidades ganharam livre curso, e agora cabe a cada indivíduo, homem ou mulher, capturá-las em pleno vôo, usando os seus próprios recursos e ferramentas” (Ibidem: 35).

Em Cidade de Deus, podemos verificar ainda a não-identidade proposta por Bauman. Para aqueles indivíduos membros de categorias consideradas inadequadas, não admissíveis, como viciados em drogas, mães solteiras, sem-teto, mendigos, entre outros, é destinada a identidade de subclasse, sendo negada qualquer outra que o sujeito possa ambicionar.

O significado da identidade da subclasse é a ausência de identidade, a abolição ou negação da individualidade, do rosto - esse objeto do dever ético e da preocupação moral. Você é excluído do espaço social em que as identidades são buscadas, escolhidas, construídas, avaliadas, confirmadas ou refutadas (BAUMAN, 2005: 46).

Reconhecemos nos personagens do filme a identidade da subclasse, ou a nãoidentidade. Algumas centenas de pessoas impedidas - social, econômica, política e culturalmente - de assumir uma posição de sujeito. Situação que pode ser ilustrada com várias passagens, por exemplo, quando Buscapé está trabalhando em um supermercado. Um grupo de crianças da Caixa Baixa - uma espécie de sub-região da Cidade de Deus entra no estabelecimento e rouba alguns produtos. Antes de saírem, elas se deparam com Buscapé, o reconhecem enquanto morador da favela e o cumprimentam. Mas o gerente percebe o furto e despede Buscapé, pois conclui que o rapaz teria facilitado o crime já que 
é morador da periferia. Nesta cena, o gerente visualiza Buscapé como bandido, numa generalização da identidade do morador do subúrbio: é da favela, logo, é criminoso.

No discurso cinematográfico de Cidade de Deus, também percebemos que a cidade do Rio de Janeiro é quase invisível, já que o filme não trata dos conflitos entre o bairro e o centro, mas de um confronto entre traficantes que, aparentemente, só atinge os habitantes da Cidade de Deus. Seria esta uma forma de abster-se de retratar a relação cidade $\mathrm{x}$ periferia? Ou, ainda, ignorar o município carioca seria a única forma de dar visibilidade à subclasse, evidenciando o que nela há de mais espetacular? Nas poucas cenas em que a trama do filme sai da favela, o complexo é retratado como lugar indiferente e distante do cartão postal do Rio de Janeiro. Com os habitantes da Cidade de Deus parece acontecer aquilo que Bauman cita como o grande receio da humanidade:

O que todos nós parecemos temer (...) é o abandono, a exclusão, ser rejeitado, ser banido, ser repudiado, descartado, despido daquilo que se é, não ter permissão de ser o que se deseja ser. Temos medo de nos deixarem sozinhos, indefesos e infelizes. (...) Receamos ser atirados ao depósito de sucata (BAUMAN, 2005: 99$100)$.

\section{Mídia, Consumo, Violência e Construções Identitárias}

Pensando as identidades apresentadas em Cidade de Deus por outra perspectiva, a do consumo, encontraremos pistas para a compreensão da exclusão social à qual é submetida a população da periferia. Conforme escreveu Ana Lúcia S. Enne (2006), quem não pode adquirir mercadorias, serviços e idéias, é deixado fora da sociedade, pois não se encaixa no padrão consumista imposto pela organização social contemporânea. Este processo de abandono do indivíduo para além das barreiras sociais resultaria na violência, já que a incapacidade de um sujeito em adaptar-se e acompanhar padrões muitas vezes inacessíveis à coletividade implicaria em revolta.

É o que acontece com Zé Pequeno. O personagem tem no ato de matar sua vingança ao sistema do qual não pode fazer parte. Assassinar com tiros a queima roupa dezenas de pessoas no motel e rir do cenário de sangue deixado para trás é uma forma de retaliação de quem, ainda criança, está às margens do consumo, do desfrute pleno da vida capitaneado pelas classes alta e média. Adulto, Zé Pequeno conquista fama de bandido perigoso no Rio de Janeiro. No entanto, ele quer mais: carros, mulheres e dinheiro; 
símbolos associados ao suposto poder que ele quer alcançar. A forma encontrada para atingir seus almejos é através da violência: ele mata para roubar, mata para ficar com a boca de fumo, mata para conseguir a mulher desejada.

Para Enne, em tempos que valores como família e igreja, por exemplo, estão esgotados para a concepção de identidades, novos elementos suprem, ou melhor, ocupam os vazios deixados por estas instituições: estamos falando do consumo e da mídia. O primeiro é uma ferramenta de afirmação social, convocação eterna para a juventude, fonte de frustração e de constante recomeço. A segunda é importante colaboradora para a ratificação da primeira. Mídia, consumo e criações identitárias são alinhavados por uma relação de poder.

No discurso midiático, há legitimação do processo de conversão de necessidades secundárias - de natureza psicológica - em primárias - de natureza fisiológica - para favorecer o consumismo. Muitas vezes, o que se vende não é a mercadoria, mas o valor simbólico agregado aos produtos. A pretensão do indivíduo é projetar-se simbolicamente através do consumo. Ter coisas, consumir coisas, implica dizer quem somos, onde estamos na organização social, em um processo de re-significação do sujeito.

Em Cidade de Deus, o traficante Bené - parceiro de Zé Pequeno desde criança, mas não tão violento - reflete bem o contexto delimitado por Enne. Ele modifica a própria forma de apresentar-se, é negro e pinta o cabelo de louro, passa a usar roupas caras e de marca, tudo para ficar parecido com os jovens de classe média. Há uma cena em que Bené chega na boca de fumo com o visual completamente diferente do garoto pobre da periferia. Ao notar que é observado com curiosidade por Zé Pequeno e os outros jovens do grupo, ele dispara: "Virei playboy". Neste momento do filme, explicita-se a vontade de ser o outro, a imitação. $\mathrm{O}$ ato não reflete apenas a cópia de um estilo, mas ao vestir-se de garoto da classe média, evidencia sua aspiração de ser aceito na sociedade, já que, enquanto periferia, Bené era visto apenas como mais um integrante de uma categoria: a dos pobres.

Simbolicamente, sair dos limites do subúrbio é ser reconhecido enquanto gente, enquanto cidadão, mesmo que esta evasão aconteça no campo do consumo, do ter para parecer ser. Interessante pontuar que o dinheiro conseguido por Bené - e também Zé Pequeno - no tráfico não é utilizado, por exemplo, em investimento na própria educação, moradia ou saúde. Mas, em posses efêmeras, objetos de afirmação social que conferem resultados momentâneos de reconhecimento na sociedade, pois temos aí o “consumo como 
estratégia não só de emulação social, mas, principalmente, de construção de referências públicas acerca do lugar social que se deseja ocupar, do estilo de vida que se busca partilhar e, fundamentalmente, da construção de si que se quer projetar” (ENNE, 2006: 22).

Assim como Enne, João Pissara Esteves (1999) também vê no consumo e na tecnologia importantes fatores para a questão da identidade na atualidade. Da mesma forma que propõe a jornalista, Esteves entende que no centro dos debates acerca do indivíduo na contemporaneidade está o duelo substancialismo - eu como essência - versus construtivismo - eu eternamente construído, criado em longo prazo e desenvolvido pela ação. Na pós-modernidade temos a valorização do individualismo ao mesmo passo que os diversos sujeitos são submetidos a um discurso controlador, centralizador, onde consumo e mídia ditam as regras do comportamento.

O embate do sujeito está em deparar-se com as limitações da realidade e sentir-se constrangido, ou mesmo humilhado, por não alcançar o ideal proposto pela sociedade consumista. Neste ponto, é perceptível a conversão das reflexões de Esteves e Enne para a conclusão de que os valores da modernidade têm propiciado para o surgimento de indivíduos pouco interativos, recolhidos em seus mundos e, muitas vezes, revoltados.

Tendo a violência como pano de fundo das relações juvenis, Carla Araújo (2001) faz uma reflexão sobre como atos de brutalidade experienciados e testemunhados na periferia interferem na construção identitária de jovens moradores do subúrbio de Belo Horizonte. A estudiosa conclui que ser ou não reconhecido enquanto habitante da favela é uma situação conflituosa para o adolescente: se se assumir morador da periferia, ele terá tranqüilidade para andar pelas ruas do bairro, por exemplo. Mas, por outro lado, este reconhecimento pode provocar constrangimentos no adolescente frente à possível discriminação da sociedade ao ser revelada sua identidade enquanto oriundo de um lugar pobre. De acordo com Araújo, “quanto maior a violência, maior será o medo e menor será a satisfação com o bairro, a ligação com o lugar, o espírito de comunidade, a identificação com os outros, a disponibilidade para ações coletivas e para a cooperação” (ARAÙJO, 2001: 151).

É o que acontece com Buscapé, por exemplo, como relatamos anteriormente. No emprego no supermercado, ser reconhecido como habitante da Cidade de Deus lhe traz problemas, já que é demitido por ser associado a um crime cometido por crianças do 
complexo. Em outra ponta, como morador da $\mathrm{CDD}^{7}$, pode circular livremente pelas ruas do bairro sem ser ameaçado pelos traficantes.

A partir do conceito eriksoniano de crise, Araújo defende que as identidades juvenis são formadas a partir das tensões vividas pelos jovens, situações de medo e coragem que forçam o adolescente a escolher que caminho seguir. Ao fazer uma opção, o sujeito estaria retomando pontos de sua história, significando experiências anteriores e construindo sua identidade. A violência vivida na periferia interfere no processo de autoreconhecimento por influenciar nas representações do jovem diante da sociedade, na forma como ele vai se re - a - presentar para o outro. Chegar à juventude e não poder fazer escolhas compromete a afirmação identitária, afetando, também, o sentimento de "ser alguém no mundo".

A fim de explicar a origem da violência entre os jovens da periferia, Araújo recorre a Enriquez, para quem os atos violentos significam uma forma do indivíduo se proteger contra a possível desintegração do próprio ego. Reagir abruptamente seria um meio de proteção às ameaças externas, quando o indivíduo se sente frágil e impotente. Nós concordamos com a autora ao pensar se não seriam exatamente impotência e fragilidade as características da juventude da periferia. Impotente por não se sentir capaz, muitas vezes, de mudar a própria sorte, a própria história; e frágil porque está suscetível a todos os males sociais. Ante este quadro, agir com agressividade seria a solução encontrada. Assim, temos o jovem que agride para não ser agredido, sendo a criminalidade uma forma de defesa. Talvez esta seja a explicação para o comportamento de Zé Pequeno, apresentado desde criança como um tipo extremamente cruel. Se por um lado o personagem sempre aparece se drogando, empunhando armas e matando, por outro não sabemos, por exemplo, se ele tem pai, mãe ou irmãos. É um ser pobre jogado à própria sorte. As ações violentas que comete podem ser encaradas como uma resposta à vida que lhe negou família, educação, saúde.

A violência, para Carla, permeia a estruturação da identidade na medida que não deixa o jovem ser autêntico, não o deixa opinar, falar e se expressar. Como expõe a autora e nós concordamos, "os sujeitos influenciam e são influenciados pelos contextos sociais, locais e globais” (ARAÙJO, 2001: 155).

\footnotetext{
${ }^{7}$ Sigla utilizada pelos personagens no filme para designar a favela Cidade de Deus
} 


\section{Considerações Finais}

Uma vez analisados os fatores envolvidos no processo de construção identitária dos jovens da periferia - a partir de representações contidas no filme Cidade de Deus -, consideramos importante concluir esta reflexão destacando o papel determinante dos meios de comunicação no processo de edificação das identidades na modernidade. Sendo a presença da mídia cada vez mais marcante na relação indivíduo versus sociedade, os meios massivos, entre eles o cinema, são responsáveis por estruturar imaginários e visões de mundo, já que os seres humanos agem a partir dos significados que lhes são atribuídos pelos meios de comunicação.

O desenrolar do filme revela a reconstrução de lembranças e a construção de uma memória comunitária, a memória da Cidade de Deus, através das histórias contadas por Buscapé - todas envolvendo, de alguma forma, jovens, transgressão e drogas. Os processos narrativos são importantes para a estruturação das identidades, uma vez que a maneira de relembrar o passado é uma forma de trazer a questão identitária para o presente. Mesmo tratando-se de uma obra de ficção, entendemos que as representações de juventude contidas em Cidade de Deus reverberam preconceitos enraizados no imaginário coletivo brasileiro.

As representações que ganham visibilidade em Cidade de Deus ajudam o espectador a criar sua imagem sobre este território que, veridicamente, se tornou um dos mais perigosos do Rio de Janeiro no começo dos anos 80. Mas, assistindo à obra de Meirelles, não temos acesso ao local em si, mas ao espaço construído “via mediação”. É um acesso aos fatos por meio de um discurso que pode originar uma falsa realidade, uma visão inadequada das histórias narradas.

Além de reforçar os papéis sociais conferidos aos jovens da periferia, o filme apresenta desfecho que ratifica a falta de opção para a classe subalterna frente à sua realidade: conviver com o banditismo e a marginalidade até a morte - esta, natural ou por assassinato em meio à guerra pelo tráfico de drogas. Apenas Buscapé tem destino diverso. Ao descobrir na fotografia um dom, depara-se também com a sua profissão. Por ironia, ou não, é com a foto de Zé Pequeno e seu bando que ele tem nas mãos uma chance de conquistar seu emprego. É com a foto de Zé Pequeno morto que ele garante a vaga em um jornal. 
A Cidade de Deus exibida na tela, talvez se pareça muito mais com a Cidade de Deus vista pela classe média, em que as categorias subalternas, bem como o seu lugar - a periferia -, são retratados como parte da identidade nacional numa forma de radiografia do Brasil para o Brasil - e, quem sabe, para o mundo. Oscilando entre a criminalidade e a escolha do caminho do bem, os tipos de jovens representados em Cidade de Deus (Fernando Meirelles, 2002) evidenciam, muitas vezes, identidades cambiantes e em permanente construção, típicas da modernidade líquida marcada pelo encurtamento das distâncias físicas, valorização do poder de consumo e presença acentuada da mídia. Neste sentido, compreendemos como nossas identidades culturais são mediadas pelas representações difundidas nos meios de comunicação, voltando-se em especial para as representações audiovisuais construídas pelo cinema nacional.

\section{Referências Bibliográficas}

ARAÚJO, Carla. As marcas da violência na construção da identidade de jovens da periferia. In. Educação e Pesquisa. Volume. 27, n.1. São Paulo: 2001 pp. 141-160.

BAUMAN, Zygmunt. Identidade. Entrevista a Benedetto Vecchi. Rio de Janeiro: Jorge Zahar Editor, 2005.

BERGER, Peter. A Construção Social da Realidade. Tratado de Sociologia do Conhecimento. Petrópolis: Vozes, 1985.

BHABHA, Homi K. O Local da Cultura. Belo Horizonte: Editora da UFMG, 2005.

CORREIA, João Carlos. Elementos para uma crítica da mediação moderna. Universidade da Beira, 2002. Interior. Disponível em: www.bocc.ubi.pt Acesso em: 30 maio 2007

ENNE, Ana Lúcia S. À perplexidade, a complexidade: a relação entre consumo e identidade nas sociedades contemporâneas. In Comunicação, Mídia e Consumo. Vol. 3 n 7. São Paulo: ESPM, 2006. pp. 11-29.

ESTEVES, João Pissara. Os media e a questão da identidade. Sobre leituras pós-modernas do fim do sujeito. Universidade Nova de Lisboa, março de 1999. Disponível em: www.bocc.ubi.pt Acesso em: 18 abril 2007

GOFFMAN, Erving. A representação do Eu na vida cotidiana. Petrópolis: Vozes, 1999.

HALL, Stuart. Quem precisa da Identidade? In. SILVA, Tomás Tadeu (org.) Identidade e Diferença: a perspectiva dos estudos culturais. Petrópolis: Vozes, 2005.

. A identidade cultural na pós-modernidade. Rio de Janeiro: DP\&A, 2006.

LINS, Paulo. Cidade de Deus. São Paulo: Companhia das Letras, 2002. 
MARZULO, Eber Pires. Os probres da favela e cite no cinema: Cidade de Deus e L'Esquive. Trabalho apresentado ao Núcleo de Pesquisa Comunicação para a Cidadania no IV Encontro dos Núcleos de Pesquisa Intercom.

Disponível em: www.intercom.org.br Acesso em: 18 julho 2007

PEREIRA, Verônica Sales. O Campos dos Sonhos - Notas sobre o imaginário e a reconstrução da Identidade. In. Comunicação \& Política. Ano 12 - No 18 - 19 - 1993. São Paulo: CBELA, 1993. pp. 63-86.

VIEIRA, Roberto Amaral. Televisão, Imaginário e Inconsciente. In. Comunicação \& Política. Ano 11- nº 16-1992. São Paulo: CBBLA. 1992. pp. 119-125.

http://cidadededeus.globo.com/ 